\title{
USO DE CALDO DE CANA-DE-AÇÚCAR PARA PRODUÇÃO DE LEVANA POR Zymomonas mobilis CCT4494
}

\author{
Sugarcane juice use for levan production by Zymomonas mobilis CCT4494
}

\author{
Fernanda Maria Pagane Guereschi Ernandes ${ }^{1}$, Crispin Humberto Garcia Cruz ${ }^{2}$
}

\begin{abstract}
RESUMO
A levana é um exopolissacarídeo constituído por unidades de frutose, unidas pó ligações $\beta(2 \rightarrow 6)$, sintetizado por vários microrganismos durante a fermentação de um meio de cultura à base de sacarose, extrato de levedura e sais minerais. Este biopolímero possui diversas aplicações tanto na área de alimentos (fixador de cores e sabores, espessante e estabilizante de vários alimentos) como também na farmacêutica (substituto de plasma sanguíneo, imunomodulador, anticarcinogênico e hipocolesterolêmico). Objetivou-se, com este trabalho, realizar um estudo comparativo da produção de levana a partir de Zymomonas mobilis CCT 4494, utilizando os meios de fermentação sintético e o caldo de cana-de-açúcar, por este ser considerado um substrato de baixo custo comercial para o processo fermentativo, devido a sua abundância e facilidade de obtenção no Brasil. Os resultados obtidos indicaram que o caldo de cana-de-açúcar, utilizado como meio de cultura alternativo, é uma matéria-prima adequada para a fermentação por Zymomonas mobilis CCT 4494, pois a sua composição possibilitou a obtenção de rendimentos de levana superiores ou semelhantes às concentrações de sacarose testadas com o meio sintético.
\end{abstract}

Termos para indexação: Biopolímero, exopolissacarídeo.

\begin{abstract}
Levan is an exopolysaccharide constituted by fructose units, $\beta(2 \rightarrow 6)$ linked, synthesized by several microorganisms during fermentation of a culture medium containing sucrose, yeast extract and mineral salts. This biopolymer has various applications as much in food area (colors and flavors fixer, thickener and stabilizer of several foods) as in pharmaceutical one (blood plasma replacement, immunomodulator, anticarcinogenic and hypocholesterolemic). The study was aimed at providing a comparative study of the production of levan from Zymomonas mobilis CCT 4494, using fermentation media sinthetic and sugarcane juice as this is considered a low cost substrate for the commercial fermentation process, due to its abundance and easy availability in Brazil. The results obtained indicated that the sugarcane juice, used as alternative culture medium, is an appropriate raw material for fermentation by Zymomonas mobilis CCT 4494 since its composition made possible the obtainment of levan yields higher or similar to the sucrose concentrations tested with the best synthetic medium.
\end{abstract}

Index terms: Biopolymer, exopolysaccharide.

(Recebido em 1 de fevereiro de 2010 e aprovado em 24 de setembro de 2010)

\section{INTRODUÇÃO}

O potencial de utilização dos polissacarídeos de origem microbiana, denominados de biopolímeros, na indústria de alimentos, é consenso na literatura existente. Diversos autores, entre eles Manresa et al. (1987), concordam que, devido às suas propriedades funcionais versáteis, os biopolímeros podem tornar-se uma ferramenta poderosa para se criar em novas texturas e, consequentemente, permitir o surgimento de novos e diferenciados produtos.

A obtenção de biopolímeros para consumo humano, entretanto, é uma tarefa mais complexa do que para a utilização em outros produtos, uma vez que estes devem ser considerados absolutamente seguros do ponto de vista alimentar e, portanto, satisfazer aos códigos e legislações alimentar em vigor. Uma amostra disso é que, apesar de a pesquisa em biopolímeros ter sido iniciada há mais de três décadas, apenas os biopolímeros xantana e gelana foram aprovados para uso alimentares nos EUA e curdlana no Japão e dextrana, apesar de ter sido o primeiro biopolímero liberado, é utilizada em produtos farmacêuticos (Sutherland, 1999). Além desses polissacarídeos, a levana tem despertado grande interesse devido às suas aplicações em diversas áreas de saúde e de alimentação humana. $\mathrm{O}$ termo "levana" refere-se a um polímero de frutose obtido a partir de reações de transfructosilação por muitas espécies de bactérias, como, por exemplo, Acetobacter suboxydans, Aerobacter levanicum, Erwinia herbicola, Streptococcus salivarius, Bacillus subtilis e Bacillus polymyxa. Inicialmente foi considerado um subproduto da

\footnotetext{
${ }^{1}$ Universidade Estadual Paulista/UNESP - Instituto de Biociências, Letras e Ciências Exatas - Campus de São José do Rio Preto - Rua Cristovão Colombo - 2265 - Jardim Nazareth - 15054-000 - São José do Rio Preto, SP - fernandaer@ig.com.br

'Universidade Estadual Paulista/UNESP - Departamento de Engenharia - São José do Rio Preto, SP
} 
fermentação alcoólica para produção de etanol, aumentado a viscosidade dos xaropes de cana-de-açúcar e assim dificultando a produção do álcool (Ernandes \& GarciaCruz, 2005, 2009).

Segundo Leibovici et al. (1979), é possível o uso de levana na medicina como um componente funcional dotado de atividade biológica para o funcionamento adequado do organismo humano. A literatura relata usos práticos de levana para vários propósitos, por exemplo, como complexo biologicamente ativo, substituto de plasma sanguíneo (Thachenko \& Sevryugina, 1989), agente prolongador da ação de fármacos, preparação de frutose altamente purificada para uso médico, fator de promoção do desenvolvimento de Bifidus, agente hipocolesterolêmico (Liepa et al., 1993) e como imunomodulador e anticarcinogênico (Calazans et al., 1997).

$\mathrm{Na}$ indústria de alimentos, a levana tem vários usos potenciais, tais como, agente espessante, fixador de cores e sabores e em produtos dietéticos. Essas aplicações valemse claramente das qualidades funcionais desse polissacarídeo, pois devido às suas propriedades reológicas e à sua capacidade de formação de gel, pode ser incorporado às formulações de produtos alimentícios para conferir características específicas às mesmas. Assim, ao passo que cresce o interesse pelo estudo e aproveitamento da levana, a tendência é que lhe sejam atribuídas novas e importantes aplicações (Tano \& Buzato, 2003).

A importância comercial da levana, em consequência desse interesse, motiva pesquisas, tanto para a identificação de novos microrganismos produtores quanto para processos que visem à otimização de sua produção em escala industrial (Reiss \& Hartmeier, 1990), tornando-se, assim, importante investigar substratos baratos e disponíveis em grandes quantidades. Diversas pesquisas têm sido conduzidas utilizando sacarose, tanto in natura (sacarose comercial) quanto contida em produtos agro-industriais (Lyness \& Doelle, 1980; Viikari, 1988; Doelle et al., 1989; Huertasdiaz et al., 1991; Farias, 2009).

A utilização de produtos agroindustriais, como a cana-de-açúcar, é uma alternativa para reduzir o custo final dos produtos de fermentação (Bruneli, 1986; Ernandes et al., 2010). Assim, o trabalho teve como objetivo realizar um estudo comparativo da produção de levana, a partir de Zymomonas mobilis CCT 4494, utilizando os meios de fermentação sintético e o caldo de cana-de-açúcar, por este ser considerado um substrato de baixo custo comercial para o processo fermentativo, devido a sua abundância e facilidade de obtenção no Brasil.

\section{MATERIAL E MÉTODOS}

\section{Microrganismo}

Foi utilizada a cepa Zymomonas mobilis CCT 4494, doada pelo Prof. Dr. Ranulfo Monte Alegre, da Faculdade de Engenharia de Alimentos da Universidade Estadual de Campinas - UNICAMP - Campinas, Brasil. Essa cultura foi mantida em meio de manutenção e estocada a $4^{\circ} \mathrm{C}$.

\section{Meios de cultura}

Meio de manutenção: a cepa foi cultivada e mantida em meio de manutenção composto em $\mathrm{g} \mathrm{L}^{-1} \mathrm{de}$ : caldo de cana clarificado (100); água destilada (30); $\mathrm{CaCO}_{3}(0,4)$; extrato de levedura $(0,4)$ e agar nutriente $(1,5)$. A bactéria foi reativada a cada 60 dias, em estufa a $30^{\circ} \mathrm{C}$ e mantida em meio de manutenção a $4^{\circ} \mathrm{C}$.

Meio de Produção: foram utilizados os meios de fermentação sintético e alternativo, ambos contendo diferentes concentrações de sacarose (10; 15,0 e 20\%). O meio sintético, proposto por Rodriguez \& Callieri (1986), foi composto em g L${ }^{-1}$ de: extrato de levedura $(5,0) ; \mathrm{KH}_{2} \mathrm{PO}_{4}$ $(1,0) ;\left(\mathrm{NH}_{4}\right)_{2} \mathrm{SO}_{4}(1,0)$ e $\mathrm{MgSO}_{4}(1,0)$. Foi utilizado o caldo de cana-de-açúcar estéril e não estéril clarificado como meio de produção alternativo. Utilizando-se um refratômetro modelo Carl Zeiss, esse caldo foi ajustado nas diferentes concentrações de sólidos solúveis (100, 150, $200 \mathrm{~g} \mathrm{~L}^{-1}$ ), sendo em seguida autoclavado. Todos os reagentes utilizados foram de grau analítico (SigmaAldrichi, EUA).

\section{Produção do biopolímero}

Pré-fermentação: a cepa foi ativada por estrias em esgotamento em tubos inclinados contendo o meio de manutenção, mantidos a $30^{\circ} \mathrm{C}$, por 24 horas. Após a incubação, foi feita a suspensão das culturas de células bacterianas pela adição de 5,0 mL de água destilada estéril, e esta foi transferida para frascos de Erlenmeyer de $250,0 \mathrm{~mL}$ contendo 50,0 mL do meio de produção com pH inicial 7,0. Os frascos foram incubados em Shaker Marconi, modelo MA 830 , a $30^{\circ} \mathrm{C}$ e $6941 \mathrm{~g}$, por 24 horas. O meio utilizado foi composto pelo meio sintético adicionado de sacarose na concentração de $20,0 \mathrm{~g} \mathrm{~L}^{-1}$

Fermentação: os frascos de Erlenmeyer de 250,0 mL contendo $50,0 \mathrm{~mL}$ do meio de produção foram inoculados com o caldo obtido da pré-fermentação. A padronização do volume de inóculo adicionado em cada frasco foi feita segundo Faria \& Garcia-Cruz (2006). O pH do meio de fermentação foi ajustado para 7,0 e a fermentação submersa se processou a $200 \mathrm{rpm}$ e por 72 horas, em um Shaker 
Marconi, modelo MA 830, com controle de temperatura $\left(30^{\circ} \mathrm{C}\right)$. Após a interrupção da fermentação, os cultivos foram centrifugados a $6941 \mathrm{~g}, 4^{\circ} \mathrm{C}$, durante 15 minutos, e as amostras obtidas foram utilizadas para as determinações analíticas.

\section{Métodos analíticos}

Análise do pH do caldo fermentado: por potenciometria em pHmetro Digmed, modelo DM20. Estimativa da concentração de levana: foi feita a precipitação do polissacarídeo pela adição de 3 volumes de etanol anidro, previamente resfriado, após centrifugação do caldo fermentado a $6941 \mathrm{~g}$ e $4^{\circ} \mathrm{C}$ durante 15 minutos. $\mathrm{O}$ precipitado de levana foi seco em estufa a vácuo a $45^{\circ} \mathrm{C}$ até peso constante, por aproximadamente 24 horas, e o seu rendimento foi calculado pela relação entre gramas do polissacarídeo obtido e as gramas consumidas da fonte de carbono. Estimativa da biomassa: foi determinada através do peso seco das células obtidas após a centrifugação do caldo de fermentação. Determinação de açúcar redutor total (ART) e açúcar redutor (AR): através do método do DNS (Miller, 1959). Teor de cinzas do polissacarídeo bruto: foi determinado pelo método descrito nas Normas Técnicas do Instituto Adolfo Lutz (1985).

\section{RESULTADOS E DISCUSSÃO}

O grande interesse pela bactéria Zymomonas mobilis como produtora de levana tem estimulado estudos sobre a utilização de diferentes substratos, condições e processos de fermentação, a fim de aumentar a sua produtividade. Contudo, as informações sobre o uso de matérias-primas naturais nesse processo são limitadas. Neste experimento, a utilisação dos meios sintético e naturais (caldo de cana-de-açúcar estéril e não estéril), acrescentados de sacarose em diferentes concentrações, como substratos, foi estudada durante o processo fermentativo para a produção de levana, pela bactéria Zymomonas mobilis CCT 4494.

Os resultados da concentração de levana sintetizada por Zymomonas mobilis CCT 4494, em relação ao conteúdo de substrato presente nos meios, durante fermentação a $30^{\circ} \mathrm{C}$, por 72 horas, podem ser observados na Tabela 1.

Sutherland (1999) relatou que vários fatores podem influenciar na síntese do produto desejado e, dependendo das condições de fermentação empregadas no processo, como por exemplo a fonte de carbono, o rendimento do biopolímero poderá reduzir ou aumentar. O relato citado pôde ser confirmado nesta pesquisa, pois Zymomonas apresentou um comportamento diferenciado dependendo do meio testado no processo fermentativo, o que ocasionou uma variação no rendimento de levana.

A produção de levana no meio de caldo de canade-açúcar foi semelhante ou superior à obtida no meio sintético (Tabela 1). Assim, confirma-se que o uso do caldo de cana-de-açúcar pode ser satisfatório para a produção desse polissacarídeo (Park et al., 1983; Huertasdiaz et al., 1991; Bekers et al., 1999).

Verificou-se que o teor de levana produzido no meio alternativo estéril não variou com o aumento de sólidos totais. Os rendimentos obtidos de levana foram de 43,0; 42,2 e 41,3\% com as concentrações de 100,0; 150,0 e 200,0 $\mathrm{g} \mathrm{L}^{-1}$ de sólidos solúveis, respectivamente (Figura 1). Han \& Clarke (1990) observaram resultados semelhantes quando utilizaram o caldo de cana como fonte de carbono e constataram que a bactéria em estudo converteu cerca de

Tabela 1 - Efeito da variação da concentração inicial de sacarose na produção de levana por Zymomonas mobilis CCT 4494, a $30^{\circ} \mathrm{C}$ e $200 \mathrm{rpm}$, por 72 h, em meio sintético e natural, utilizando caldo de cana-de-açúcar estéril e não estéril.

\begin{tabular}{|c|c|c|c|c|c|c|c|c|c|}
\hline \multirow[t]{2}{*}{ Parâmetros } & \multicolumn{3}{|c|}{$\begin{array}{c}\text { Caldo de cana-de-açúcar } \\
\text { estéril } \\
\text { Sacarose }\left(\mathrm{g} \mathrm{L}^{-1}\right)\end{array}$} & \multicolumn{3}{|c|}{$\begin{array}{c}\text { Caldo de cana-de-açúcar } \\
\text { não estéril } \\
\text { Sacarose }\left(\mathrm{g} \mathrm{L}^{-1}\right)\end{array}$} & \multicolumn{3}{|c|}{$\begin{array}{c}\text { Meio } \\
\text { sintético } \\
\text { Sacarose }\left(\mathrm{g} \mathrm{L}^{-1}\right)\end{array}$} \\
\hline & 100 & 150 & 200 & 100 & 150 & 200 & 100 & 150 & 200 \\
\hline $\mathrm{pH}$ final & 5,1 & 5,6 & 5,5 & 2,1 & 2,8 & 2,8 & 4,4 & 4,5 & 4,4 \\
\hline $\mathrm{MC}\left(\mathrm{g} \mathrm{L}^{-1}\right)$ & 1,9 & 2,2 & 2,7 & 2,6 & 2,9 & 3,3 & 3,3 & 4,2 & 4,6 \\
\hline Z. mobilis $\mathrm{L}\left(\mathrm{g} \mathrm{L}^{-1}\right)$ & 43,0 & 63,3 & 82,6 & - & - & - & 26,1 & 42,4 & 85,4 \\
\hline CCT4494 L (\%) & 43,0 & 42,2 & 41,3 & - & - & - & 26,1 & 28,3 & 42,7 \\
\hline $\operatorname{ART}\left(\mathrm{g} \mathrm{L}^{-1}\right)$ & 2,2 & 5,8 & 8,0 & nd & nd & nd & 39,3 & 43,3 & 15,3 \\
\hline $\mathrm{C}(\%)$ & 1,2 & 0,9 & 1,4 & nd & nd & nd & 0,7 & 0,7 & 0,7 \\
\hline
\end{tabular}

MC: massa celular; L (levana); ART: açúcares redutores totais; C: cinzas; - : sem produção de levana; nd: não determinado. 
46,0\% da molécula de sacarose em levana. Outros autores, empregando diferentes cepas de Zymomonas mobilis, verificaram que a produção de levana foi bastante diversificada. Ananthalakshmy \& Gunasekaran (1999) obtiveram 12,6 $\mathrm{g} \mathrm{L}^{-1}$ de levana, a partir de Zymomonas mobilis B-4286, em 150,0 g L-1 de sacarose, após 16 horas de cultivo.

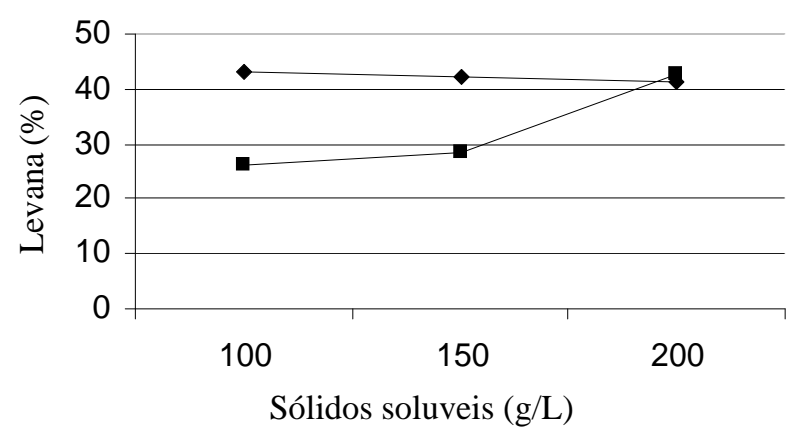

Figura 1 - Rendimento de levana (\%) durante a fermentação de Zymomonas mobilis CCT 4494 no meio alternativo (caldo de cana-de-açúcar estéril) e no meio sintético, adicionados de concentrações de 100,0; 150,0 e 200,0 ( $\left.\mathrm{g} \mathrm{L}^{-1}\right)$ de sólidos solúveis. - - meio alternativo (caldo de canade-açúcar estéril); - - meio sintético.

A produção desse biopolímero em meio sintético, entretanto, aumentou $28,3 \%$ para $42,7 \%$ quando as concentrações de sacarose de 150,0 e $200,0 \mathrm{~g} \mathrm{~L}^{-1}$ foram testadas (Figura 1). Algumas pesquisas também concluíram que altas concentrações de sacarose inicial influenciaram na formação do biopolímero durante o processo fermentativo com linhagens de Zymomonas mobilis, considerando as condições de fermentação empregadas em cada uma. Viikari \& Gisler (1986) variaram a concentração inicial de sacarose $\left(50,0 ; 100,0\right.$ e 150,0 $\left.\mathrm{g} \mathrm{L}^{-1}\right)$ e obtiveram máxima formação de levana com $150,0 \mathrm{~g} \mathrm{~L}^{-1} \mathrm{de}$ substrato para a cepa Zymomonas mobilis estudada. Mello et al. (2007) estudaram a maximização de levana, por via fermentativa, pela linhagem Zymomonas mobilis ZAG-12 utilizando sacarose em altas concentrações e os resultados demonstraram que as melhores condições para a produção em batelada ocorreram com $250,0 \mathrm{~g} \mathrm{~L}^{-1} \mathrm{de}$ sacarose inicial, $100 \mathrm{rpm}$ de agitação, a $20^{\circ} \mathrm{C}$.

É importante salientar que Zymomonas mobilis CCT 4494 apresentou alta tolerância às elevadas concentrações de substrato testado, devido à sua elevada capacidade de regulação osmótica e ao eficiente sistema de transporte de glicose (Struch et al., 1991). A glicose é transportada em alta velocidade através da membrana plasmática, sendo sua condução facilitada pelo sistema de difusão. Assim, a concentração intracelular rapidamente alcança nível limite em relação às concentrações externas de glicose (Belaich et al., 1968).

Zymomonas mobilis CCT 4494 não sintetizou o biopolímero no meio alternativo não estéril. Esse fato pode estar relacionado a possível presença de microrganismos contaminantes no caldo fermentado, pois este apresentou características diferentes tais como excesso de espumas, coloração e odor diferentes, quando comparadas às outras fermentações realizadas. Diversos autores relataram, em suas pesquisas, que, do ponto de vista microbiológico, o caldo de cana retém microrganismos que fazem parte de sua biota epifítica e da terra aderida aos colmos, raízes e folhas. Estima-se que a cana saudável pode conter $10^{1} \mathrm{a}$ $10^{8}$ bactérias por grama, sendo as mais frequentes: Flavobacterium, Xanthomonas, Pseudomonas, Enterobacter, Erwinia, Lactobacillus, Leuconostoc, Bacillus e Corynebacterium (Cleto et al., 2009). Entre as leveduras, podem-se citar: Torulopsis, Candida, Saccharomyces, Torula e Pichia (Bruneli, 1986; Silva \& Canho, 1990; Kitoko et al., 2004; Oliveira et al., 2006). Baseando-se na literatura e nas análises realizadas com as amostras do caldo de fermentação obtido após o processo fermentativo com o meio natural não estéril, a competição de substrato pelos microrganismos contaminantes e pela cepa Zymomonas ocasionou uma redução no seu crescimento ocasionando e, consequentemente, a ausência do biopolímero.

Além disso, é importante ressaltar que, após a análise dos valores de $\mathrm{pH}$ final nos caldos de fermentação obtidos com os três meios testados, observou-se uma redução drástica no $\mathrm{pH}$ final nas amostras com o meio natural não estéril. A Figura 2 demonstra o perfil de $\mathrm{pH}$ final, após as 72 horas de fermentação, com as diferentes matérias primas em estudo (meios caldos de cana estéril e não estéril e meio sintético).

Observou-se que, além do caldo fermentado obtido com o meio natural não estéril apresentar características diferentes dos demais meios de fermentação testados, constatou-se também uma queda pronunciada do $\mathrm{pH}$ inicial de 7,0 para 2,6, tornando-se esses, fatores indesejáveis para que Zymomonas pudesse utilizar o substrato presente no meio não só para seu desenvolvimento como também para convertê-lo em biopolímero.

Analisando a variação do $\mathrm{pH}$ final nos meios em que, houve síntese de levana, observou-se que, no caldo estéril, ocorreu uma redução de 7,0 para 5,1 sendo esta variação menor que a observada no meio sintético, cujo 
menor pH final foi de 4,4 (Figura 2). Valores semelhantes foram observados por Doelle et al. (1989), que relataram que o pH final, depois de 3 dias, à temperatura de $30^{\circ} \mathrm{C}$ em meio padrão, ficou entre 4,8 a 5,2, e que esta redução representa a formação de ácidos e a tolerância do microrganismo a valores de $\mathrm{pH}$ baixos (Alegre et al., 2005).

O comportamento do crescimento de Zymomonas mobilis CCT 4494 foi dependente dos meios de fermentação testados, apresentado valores de biomassa maiores no meio sintético em relação aos do caldo de cana estéril. Na maior concentração de substrato $\left(200,0 \mathrm{~g} \mathrm{~L}^{-1}\right)$, a massa celular foi de 4,6 $\mathrm{g} \mathrm{L}^{-1}$ com o meio sintético, e de $2,7 \mathrm{~g} \mathrm{~L}^{-1}$, com o meio alternativo estéril, apesar dos rendimentos de levana não acompanharem essa redução (Figura 3).

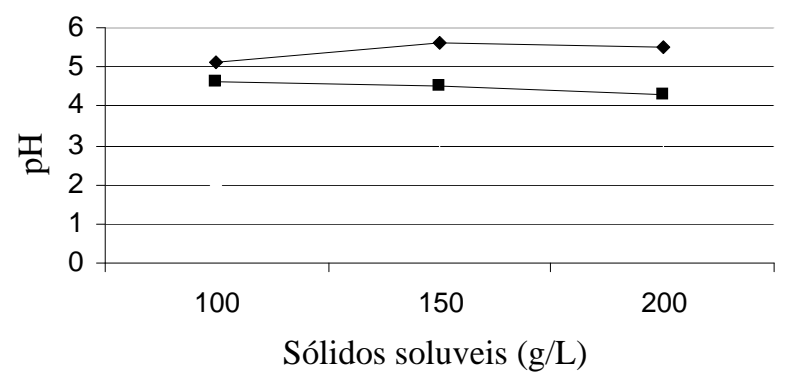

Figura 2 - Variação do pH durante a fermentação de Zymomonas mobilis CCT 4494 no meio alternativo (caldo de cana-de-açúcar estéril e não estéril) e no meio sintético, adicionados de concentrações de 100,0; 150,0 e 200,0 ( $\left.\mathrm{g} \mathrm{L}^{-1}\right)$ de sólidos solúveis. - - meio alternativo (caldo de cana-

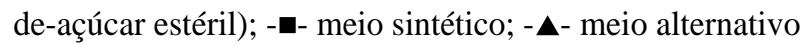
(caldo de cana-de-açúcar não estéril).

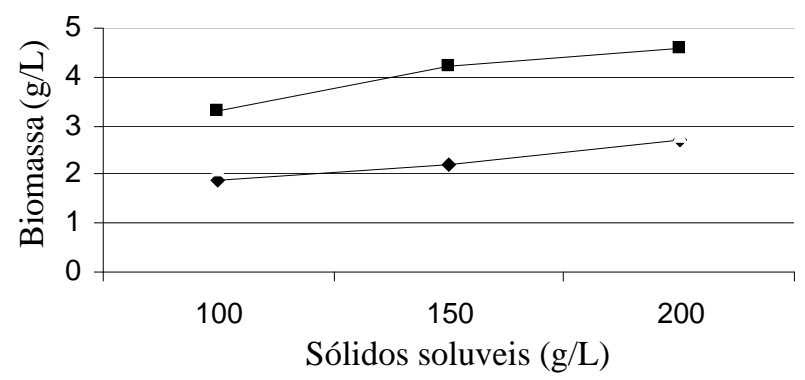

Figura 3 - Valores de biomassa $\left(\mathrm{g} \mathrm{L}^{-1}\right)$ obtida durante a fermentação de Zymomonas mobilis CCT 4494 no meio alternativo (caldo de cana-de-açúcar estéril e não estéril) e no meio sintético, adicionados de concentrações de 100,0; 150,0 e 200,0 ( $\left.\mathrm{g} \mathrm{L}^{-1}\right)$ de sólidos solúveis. - - meio alternativo (caldo de cana-de-açúcar estéril); - - - meio

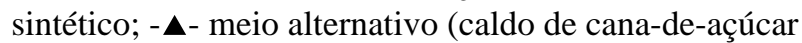
não estéril).
De acordo com Tano \& Buzato (2003), alguns dos componentes presentes no caldo de cana-de-açúcar podem causar inibição do crescimento de Zymomonas mobilis. Os níveis relativamente elevados de alguns sais inorgânicos, especialmente cloreto de potássio e alguns íons como cálcio e magnésio, podem apresentar um efeito inibidor significativo na fermentação, além da competição de outros microrganismos. Entretanto, Jerez \& Mancilha (1994) conduziram um estudo sobre métodos e condições de fermentação de melaço de cana-de-açúcar por Zymomonas mobilis CP4 e seu efeito sobre os parâmetros cinéticos de fermentação. Os autores avaliaram o efeito da temperatura, controle de $\mathrm{pH}$ e efeito de íons $\mathrm{Ca}^{++}, \mathrm{K}^{+}, \mathrm{Cl}^{-}$e $\mathrm{Mg}^{++}$em meio de fermentação com sacarose. Em melaço de cana-de-açúcar, foram estudados os efeitos da clarificação e suplementação com nutrientes. Os tratamentos de clarificação do melaço removeram $\mathrm{Ca}^{++}$e $\mathrm{K}^{+}$, mas não aumentaram o rendimento da fermentação. Foi observado que $\mathrm{Ca}^{++}, \mathrm{K}^{+}$e $\mathrm{Cl}^{-}$são inibidores do crescimento de Zymomonas mobilis $\mathrm{CP} 4$, mas o $\mathrm{Mg}^{++}$ não apresentou efeito inibitório em nenhuma das condições estudadas. Portanto, segundo os autores, é necessária a suplementação do melaço para aumentar os rendimentos da produção de levana.

\section{CONCLUSÕES}

De acordo com os resultados obtidos nesta pesquisa, conclui-se que o caldo de cana-de-açúcar, previamente clarificado e esterilizado, é uma matéria-prima promissora para a produção de levana, pois apresenta a vantagem de ser considerado um substrato de baixo custo comercial para o processo fermentativo devido à abundância e facilidade de aquisição em nosso país. Contudo, em virtude da sua composição, estudos futuros sobre a suplementação com nitrogênio e alguns sais minerais, especialmente fósforo e magnésio, devem ser realizados para otimização da produção de levana.

\section{AGRADECIMENTOS}

Agradecimento a Fundação de Amparo a Pesquisa (FAPESP).

\section{REFERÊNCIAS BIBLIOGRÁFICAS}

ALEGRE, R.M.; WENDT, R.; RIGO, M. Levan production by isolated mutants of Zymomonas mobilis. Revista de Ciências Exatas e Naturais, Londrina, v.7, p.103-112, 2005.

ANANTHALAKSHMY, V.K.; GUNASEKARAN, P. Isolation and chacterization of mutants from levanproducing Zymomonas mobilis. Journal of Bioscience and Bioengineering, Osaka, v.87, p.214-217, 1999. 
BEKERS, M.; LINDE, R.; DANILLEVICH, A.; KAMINSKA, E.; UPITE, D.; VIGANTS, A.; SCHERBAKA, R. Sugar beet diffusion and syrup as media for ethanol and levan production by Zymomonas mobilis. Food Biotechnology, Stuttgart, v.13, p.107-119, 1999.

BELAICH, J.P.; SENEZ, J.C.; MURGIER, M.

Microcalcimetric study of glucose permeation in microbial cells. Journal of Bacteriology, Washington, v.95, p.1750-1757, 1968.

BRUNELI, A. Mercado de cana-de-açúcar. Alimentos e Tecnologia, São Paulo, v.9, p.25-27, 1986

CALAZANS, G.M.T.; LOPES, C.E.; LIMA, R.M.O.C.; DEFRANCA, F.P. Antitumor activity of levans produced by Zymomonas mobilis strains. Biotechnology Letters, Kew, London, v.19, p.19-21, 1977.

CLETO, F.V.G.; RAVANELI, G.C.; MUTTON, M.J.R. Effects of corn meal and sulphuric acid on the production of cachaça. Ciência e Agrotecnologia, Lavras, v.33, p.1379-1384, 2009.

DOELLE, M.; MILLICHIP, R.; DOELLE, H.W. Production of ethanol from corn using inoculum cacading of Zymomonas mobilis. Process Biochemistry, London, v.15, p.137-140, 1989.

ERNANDES, F.M.P.G.; BOSCOLO, M.; GARCIA-CRUZ, C.H. Influencia da composição do meio para produção de etanol, por Zymomonas mobilis. Acta Scientiarum Tecnology, Maringá, v.32, n.1, p.21-26, 2010.

ERNANDES, F.M.P.G.; GARCIA-CRUZ, C.H. Análise dos parâmetros cinéticos para produção de levana por Zymomonas mobilis utilizando fermentação submersa. Acta Scientiarum Technology, Maringá, v.31, n.1, p.3541, 2009.

ERNANDES, F.M.P.G.; GARCIA-CRUZ, C.H. Levana bacteriana: aspectos tecnológicos, características e produção. Semina: Ciências Agrárias, Londrina, v.26, p.15-19, 2005.

FARIA, L.H.G.B.; GARCIA-CRUZ, C.H. Influência da taxa nitrogênio/carbono durante a produção de polissacarídeos por uma bactéria isolada do solo. Higiene Alimentar, São Paulo, v.145, p.1-10, 2006.
FARIAS, D. Potencial amilolítico do grão de milho maltado no processo de sacarificação do mesmo cereal. Ciência e Agrotecnologia, Lavras, v.33, p.855-862, 2009.

HAN, Y.W.; CLARKE, M.A. Production and characterization of microbial levan. Journal of Agriculture and Food Chemistry, Easton, v.38, p.393396, 1990.

HUERTASDIAZ, H.; CACHO, C.L.; BERNARD, L. Fermentation of sugarcane juice and blackstrap molasses by Zymomonas mobilis. Journal of Agriculture of the University of Puerto Rico, Caracas, v.75, p.43-50, 1991.

INSTITUTO ADOLFO LUTZ. Normas analíticas do Instituto Adolfo Lutz. In:___ Métodos químicos e físicos para análise de alimentos. 3.ed. São Paulo, 1985. p.27.

JEREZ, M.C.D.; MANCILHA, I.M. Produccion de etanol por Zymomonas mobilis en proceso continuo de fermentacion: efecto de la velocidad de dilucion en la cinetica de la fermentation. Revista Latinoamericana de Microbiologia, Mexico, v.12, p.35-40, 1994.

KITOKO, P.M.; OLIVEIRA, A.C.; SILVA, M.L.; LOURENÇÃO, M.; AGUIAR, E.F. Avaliação microbiológica do caldo de cana comercializado em Vitória, Espírito Santo, Brasil. Higiene Alimentar, São Paulo, v.18, p.73-77, 2004.

LEIBOVICI, J.; BORITA, A.; SANDBANK, U.; WOLMAN, M. Role of macrophages and polymorphs in the levan-induced inhibition of Lewis lung carcinoma in C57BL mice. British Journal of Cancer, London, v.40, p.597-606, 1979.

LIEPA, V.; ZAKENFELDS, G.; VOLPE, E.; KORONOVA, Z.; LAPSA, R.; LAIVENIEKS, M.; BEKERIS, M.; OSPISHIL, I. Levan prolongs the lifespan of tumor-bearing or irradiates mice, and enhances the antitumor activity of leukocytes.

Proceedings of the Latvian Academy of Sciences, Baltimore, v.5, p.59-64, 1993.

LYNESS, E.W.; DOELLE, H.W. Effect of temperature on sucrose to ethanol conversion by Zymomonas mobilis strains. Biotechnology Letters, Kew, v.2, p.549-554, 1980. 
MANRESA, A.; ESPUNY, M.J.; GUINEA, J. Characterization and production of a new extracellular polymer from Pseudomonas sp GPS-910. Applied Microbiology and Biotechnology, Berlin, v.26, p.347-351, 1987.

MELO, I.R.; PIMENTEL, M.F.; LOPES, C.E.; CALAZANS, G.M.T. Application of fractional factorial design to levan production by Zymomonas mobilis. Brazilian Journal of Microbiology, São Paulo, v.38, p.45-51, 2007.

MILLER, G.L. Use of DNS acid reagent for the determination of reducing sugars. Analytical Chemistry, Washington, v.31, p.426-428, 1959.

OLIVEIRA, A.C.G.; SEIXAS, A.S.S.; SOUSA, C.P.; SOUZA, C.W.O. Microbiological evaluation of sugarcane juice sold at street stands and juice handling conditions in São Carlos, São Paulo, Brazil. Cadernos de Saúde Pública, Rio de Janeiro, v.22, p.1111-1114, 2006.

PARK, Y.K.; MORTATTI, M.P.L.; SATO, H.H. Study of levan formation during fermentation of Zymomonas mobilis on sucrose. Biotechnology Letters, Kew, v.5, p.515-518, 1983.

REISS, M.; HARTMEIER, W. Levan production with a flocculent strain of Zymomonas mobilis. Food Biotechnology, Stuttgart, v.4, p.69-75, 1990.

RODRIGUEZ, E.; CALLIERI, D.A.S. High yield conversion of sucrose into ethanol by a flocculent
Zymomonas sp. isolated from sugarcane juice.

Biotechnology Letters, Kew, v.8, p.745-748, 1986.

SILVA, N.; CANHOS, V.P. Caracterização da microbiota bacteriana contaminante do caldo de cana durante a etapa de resfriamento em torre no processo de produção de álcool. Coletânea do Instituto de Tecnologia de Alimentos, Campinas, v.20, p.60-72, 1990.

STRUCH, T.; NEUSS, B.; BRINGER-MEYER, S.; SAHM, H. Osmotic adjustment of Zymomonas mobilis to concentrated glucose solutions. Applied Microbiology andBiotechonology, Berlin, v.34, p.518-523, 1991.

SUTHERLAND, I.W. Polysaccharases for microbial exopolysaccharides. Carbohydrate Polymers, Barking, v.38, p.319-328, 1999.

TANO, M.S.; BUZATO, J.B. Effect of the presence of initial ethanol on ethanol production in sugar cane juice fermented by Zymomonas mobilis. Brazilian Journal of Microbiology, São Paulo, v.34, p.242-244, 2003.

THACHENKO, A.A.; SEVRYUGINA, T.V. Biosynthesis of levan by Bacillus polymyxa. Translated from Microbiology, Leningrad, v.58, p.457-461, 1989.

VIIKARI, L. Carbohydrate metabolism in Zymomonas: critical review. Biotechnology Letters, Kew, v.10, p.236-261, 1988.

VIIKARI, L.; GISLER, R. By-products in the fermentation of sucrose by different Zymomonas strains. Applied Microbiology and Biotechnology, Berlin, v.23, p.240-244, 1986. 